\title{
The Impact of Syncope During Clinical Presentation of Sustained Ventricular Tachycardia on Total and Cardiac Mortality in Patients with Chronic Chagasic Heart Disease
}

\author{
Luiz Roberto Leite, Guilherme Fenelon, Ângela Tavares Paes, Angelo Amato Vincenzo de Paola
}

São Paulo, SP - Brazil

\begin{abstract}
Objective - To assess the impact of syncope during sustained ventricular tachycardia on total and cardiac mortality in patients with chronic chagasic heart disease.

Methods - We assessed 78 patients with sustained ventricular tachycardia and chronic Chagas' heart disease. The mean age was $53 \pm 10$ years, 45 were males, and the mean ejection fraction was $49.6 \pm 13 \%$. The patients were divided into 2 groups according to the presence $(G I=45)$ or absence $(G I I=33)$ of syncope during sustained ventricular tachycardia.
\end{abstract}

Results - After a mean follow-up of 49 months, total mortality was $35 \%$ (28 deaths), 22 deaths having a cardiac cause (78.6\%). No difference was observed in total $(33.3 \% x$ $39.4 \%)$ and cardiac (26.7\% x 30.3\%) mortality, or in nonfatal sustained ventricular tachycardia between GI and GII patients (57.6\% $54.4 \%$, respectively). However, the presence of syncope during recurrences was significantly greater in those patients who had had the symptom from the beginning (65.4\% $\times 18.1 \%, p<0.01)$.

Conclusion - Syncope during the presentation of sustained ventricular tachycardia is not associated with an increase in total or cardiac mortality in patients with chronic Chagas' heart disease. However, syncope during the recurrence ventricular tachycardia is greater in patients experiencing syncope in the first episode, of sustained ventricular tachycardia.

Key words: syncope, sustained ventricular tachycardia, chronic Chagas' heart disease

Universidade Federal de São Paulo - Escola Paulista de Medicina

Mailing address: Luiz Roberto Leite - Setor de Eletrofisiologia Clínica

- Rua Napoleão de Barros, 593 - 04024-002 - São Paulo, SP, Brazil -

E-mail: eletrof@uol.com.br

English version by Stela Maris C. e Gandour
Identification of patients at high risk of cardiac death is fundamental in cardiological investigation. The importance of syncope during the clinical presentation of sustained ventricular tachycardia, as a prognostic factor, was extensively studied in patients with coronary artery disease, and it was considered a worse prognosis when compared with hemodynamically well-tolerated sustained tachyarrhythmias ${ }^{1-5}$. In chronic chagasic heart disease, however, the relevance of syncope during clinical presentation of sustained ventricular tachycardia is not totally understood, and its incidence is variable according to reports published in the literature ${ }^{6-10}$. The objective of this study was to assess the impact of syncope during the clinical presentation of sustained ventricular tachycardia on total, cardiac, and sudden death in patients with chronic chagasic heart disease.

\section{Methods}

We consecutively assessed 78 patients with chronic Chagas' heart disease after an episode of sustained ventricular tachycardia in the clinical electrophysiology section of the Hospital São Paulo of the Universidade Federal de São Paulo. Forty-five patients were males and 33 were females, their mean age being $53 \pm 10$ years ( 29 to 74 ). The mean left ventricular ejection fraction was $49.6 \% \pm 13 \%$ (24 to 76 ), and $24(30.8 \%)$ patients had ejection fraction $<40 \%$. In this population, $11.5 \%$ of the patients had advanced heart failure (NYHA functional class III or IV).

All patients had their diagnosis of Chagas' disease confirmed by serological tests, and the presence of heart disease was confirmed by alterations on the 12-lead electrocardiogram, chest radiography, ambulatory electrocardiographic monitoring (Holter), echocardiogram, radionuclide ventriculography, and left ventricular angiography. Monomorphic spontaneous sustained ventricular tachycardia was recorded on an electrocardiogram or on Holter monitoring in all patients. Coronary angiography was performed in all males older than 35 years and in all females older than 40 years. 
The electrophysiological study with programmed ventricular stimulation was performed in all patients, according to stimulation techniques previously reported ${ }^{10-13}$, using up to 3 extrastimuli with a minimum coupling of $200 \mathrm{~ms}$, under 2 cycles of basal stimulation (600 and $450 \mathrm{~ms})^{10-13}$.

The patients were classified according to the presence (group I) or absence (group II) of syncope during clinical presentation of sustained ventricular tachycardia.

To comply with the objectives of the study, the following definitions were used: 1) syncope, the sudden loss of consciousness followed by spontaneous recovery, considered present when the episode occurred during electrocardiographic monitoring or when, after regaining consciousness, the patient was in sustained ventricular tachycardia;2) sustained ventricular tachycardia, which is the presence of consecutive ventricular beats with a heart rate $>100 \mathrm{bpm}$ and duration $>30$ s, or the need for immediate reversion, when hemodynamic impairment occurs; 3) sudden cardiac death, in the case of a witnessed death, occurring within 1 hour at most after symptom onset in a clinically stable patient, or in the case of an unwitnessed death, the patient should have been asymptomatic within the 24 hours preceding death; 4 ) cardiac death, the sum of sudden death and that resulting fromprogression of heart failure or thromboembolic events; 5) recurrence of nonfatal sustained ventricular tachycardia, recorded on an electrocardiogram or Holter, with no evolution to ventricular fibrillation or cardiopulmonary arrest.

After hospital discharge, the patients were assessed monthly during the first 6 months, and then bimonthly during the first year. During follow-up, the following events were defined: death due to cardiac causes (sudden and nonsudden), to noncardiac causes, deaths after a maximum follow-up of 10 years, and recurrence of nonfatal sustained ventricular tachycardia. The initial treatment was considered the one used since hospital discharge, and maintenance treatment comprised the drugs used since the last contact.

Continuous variables were presented as mean \pm standard deviation. For comparison between the groups, the chi-square test or Fisher exact test, when appropriate, was used for qualitative variables, and Student $t$ test was used for quantitative variables. Survival curves were depicted according to the Kaplan-Meier method and compared by the log-rank test.

\section{Results}

Of the 78 patients, 45 (57.7\%) experienced syncope during clinical presentation of sustained ventricular tachycardia and comprised group I; the 33 (42.3\%) patients who did not experience syncope comprised group II. Other symptoms present during sustained ventricular tachycardia were palpitation in 67 patients $(\mathrm{GI}=39$ and $\mathrm{GII}=28$, $\mathrm{p}=0.50)$ and dyspnea in 38 patients $(\mathrm{GI}=21$ and $\mathrm{GII}=17$, $\mathrm{p}=0.40$ ). The clinical characteristics of both groups are shown in table I. No difference between group I and II patients was observed in regard to age $(52.5 \pm 10$ and $53.2 \pm 10$, $\mathrm{p}=0.31$ ), sex, presence of advanced heart failure, left ventricular ejection fraction $(48.1 \pm 13$ and $51.6 \pm 13, \mathrm{p}=0.8)$, number of patients with ejection fraction $<40 \%$ [GI $=16(35.6 \%)$ and $\mathrm{GII}=8(24.2 \%),(\mathrm{p}=0.21)]$, and segmentary alteration $(77.8 \%$ and $69.7 \%, \mathrm{p}=0.29)$. Density of isolated ventricular extrasystoles per hour (193 vs $91, \mathrm{p}=0.04$ ) and nonsustained ventricular tachycardia in 24 hours ( 70 vs $8, p=0.25$ ) recorded on the initial Holter was greater in the patients with syncope.

Most patients had electrocardiographic alterations, which were present in $80 \%(n=36)$ of the patients with syncope and $78.8 \%(\mathrm{n}=26)$ of those without. The most common electrocardiographic findings were as follows: right bundle-branch block associated with left anterosuperior divisional block (29.5\%), isolated right bundle-branch block (10.3\%), isolated left bundle-branch block (10.3\%), and left divisional anterosuperior block (11.5\%). None of these alterations predominated in the patients experiencing or not experiencing syncope.

The frequency cycle of clinical sustained ventricular tachycardia was analyzed in 49 patients $(\mathrm{GI}=25, \mathrm{GII}=24)$. The mean frequency cycle in GI was $314 \mathrm{~ms}$ [95\% CI 282-347], and, in GII, it was $309 \mathrm{~ms}$ [95\% CI 282-337], with no statistically significant difference between the groups $(\mathrm{p}=0.79)$.

During electrophysiological study with programmed ventricular stimulation, sustained ventricular tachycardia was induced in 75 patients. The frequency cycle of induced sustained ventricular tachycardia was 296 ms [95\% CI 273319 ] in the patients experiencing syncope and $325 \mathrm{~ms}$ [95\% CI 299-351] in those not experiencing syncope (tab. I). A tendency toward a shorter frequency cycle of induced sustained ventricular tachycardia was observed in the patients experiencing syncope $(\mathrm{p}=0.08)$.

All chagasic patients with sustained ventricular tachycardia were successfully treated and were available for ambulatory follow-up. The cardiac drugs used during the last contact are listed in table II. At the end of follow-up, 71 patients were using amiodarone, $41(91.1 \%)$ in the group of

\begin{tabular}{|c|c|c|c|}
\hline \multicolumn{4}{|c|}{$\begin{array}{l}\text { Table I - Baseline characteristics of patients with sustained ventricular } \\
\text { tachycardia and chronic chagasic heart disease according to the } \\
\text { presence of syncope during clinical presentation of the arrhythmia }\end{array}$} \\
\hline & $\begin{array}{l}\text { Group I } \\
\text { with syncope } \\
\quad(\mathrm{N}=45)\end{array}$ & $\begin{array}{l}\text { Group II } \\
\text { without syncope } \\
\quad(\mathrm{N}=33)\end{array}$ & $\mathrm{P}$ \\
\hline Age (years) & $52.5 \pm 10$ & $53.2 \pm 10$ & 0.31 \\
\hline Male sex $(\%)$ & $29(54.4)$ & $16(48.5)$ & 0.12 \\
\hline Abnormal ECG $(\%)$ & $36(80)$ & $26(78.8)$ & 0.91 \\
\hline Segmentary alteration $(\%)$ & $35(77.8)$ & $23(69.7)$ & 0.29 \\
\hline Ejection fraction & $48.0 \pm 13$ & $51.6 \pm 13$ & 0.79 \\
\hline Ejection fraction $<40 \%(\%)$ & $16(35.6)$ & $8(24.2)$ & 0.21 \\
\hline $\begin{array}{l}\text { NYHA Functional } \\
\text { class III and IV (\%) }\end{array}$ & $13.3 \%$ & $9.1 \%$ & 0.41 \\
\hline $\begin{array}{l}\text { Frequency cycle } \\
\text { of clinical SVT }(\mathrm{ms})\end{array}$ & $314 \pm 78$ & $309 \pm 65$ & 0.79 \\
\hline $\begin{array}{l}\text { Frequency cycle } \\
\text { of induced SVT }(\mathrm{ms})\end{array}$ & $296 \pm 78$ & $325 \pm 71$ & 0.08 \\
\hline Isolated $\mathrm{VE} / \mathrm{h}$ & 193 & 91 & $0.04 *$ \\
\hline $\mathrm{NSVT} / 24 \mathrm{~h}$ & 70 & 8 & 0.25 \\
\hline Follow-up duration (months) & $47 \pm 27$ & $42 \pm 25$ & 0.80 \\
\hline
\end{tabular}


patients experiencing syncope and $30(90.9 \%)$ in those not experiencing syncope $(\mathrm{p}=0.21)$. Six patients were using sotalol, and 2 patients were not using antiarrhythmic drugs. Catheter ablation was performed in 34 patients, 18 (40\%) patients in group I and $16(45 \%)$ patients in group II $(\mathrm{p}=0.50)$. The use of a definitive pacemaker for bradyarrhythmias did not differ in the 2 groups. Six $(13.3 \%)$ patients experiencing syncope and $7(21.2 \%)$ not experiencing syncope used pacemakers implanted for bradyarrhythmias.

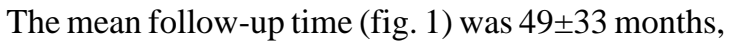
and all patients were followed up for at least 1 year, except 1 patient in GI who was followed up for 10 months. In group I, the mean follow-up was $51 \pm 32$ months, and 7 (15.5\%) patients in this group were followed up for less than 24 months;

\begin{tabular}{|c|c|c|c|}
\hline \multicolumn{4}{|c|}{ Table II - Pharmacological and antiarrhythmic treatment } \\
\hline & $\begin{array}{c}\text { Group I } \\
\text { with syncope } \\
\mathrm{N}=(45)\end{array}$ & $\begin{array}{c}\text { Group II } \\
\text { without syncope } \\
\mathrm{N}=(33)\end{array}$ & $\mathrm{P}$ \\
\hline Digitalis & $10(22.2 \%)$ & $7(21.2 \%)$ & 1.00 \\
\hline ACE I & $28(62.2 \%)$ & $24(72.7 \%)$ & 0.46 \\
\hline Diuretics & $15(33.3 \%)$ & $17(51.5 \%)$ & 0.16 \\
\hline Amiodarone & $41(91.1 \%)$ & $390.2 \pm 73.5$ & 0.21 \\
\hline Dose média (mg) & $30(90.9 \%)$ & $386.6 \pm 68.1$ & 0.83 \\
\hline Sotalol & $5(15.1 \%)$ & $1(3 \%)$ & 0.31 \\
\hline mean dose (mg) & $224 \pm 35$ & 160 & \\
\hline Catheter ablation & $18(40 \%)$ & $16(45 \%)$ & 0.50 \\
\hline Definitive pacemaker & $6(13.3 \%)$ & $7(21.2 \%)$ & 0.75 \\
\hline
\end{tabular}

in group II, the mean follow-up was $46 \pm 32$ months, and 5 $(15.1 \%)$ patients were followed up for less than 24 months.

Total mortality was $35 \%$ (28 deaths). No difference between the groups was observed in regard to total mortality; $15(33.3 \%)$ patients died in group I, and $13(39.4 \%)$ patients died in group II (tab. III). The survival curve showed that, during the entire clinical follow-up, total mortality was similar in both groups (fig. 2).

Of the deaths in the 78 patients, $28.2 \%$ had cardiac causes, accounting for $78.6 \%$ of deaths in this population (22 deaths). Figure 3 shows the curve of accumulated cardiac deaths in the 78 patients, which did not statistically differ between groups I and II ( $\mathrm{p}=0.64), 12$ (26.7\%) and 10 $(30.3 \%)$ being the deaths from cardiac causes, respectively. Most cardiac deaths occurred suddenly. Of all cardiac deaths, $63.6 \%$ were considered sudden (14 deaths). Sudden death accounted for $50 \%(6 / 12)$ of the cardiac deaths in group I patients and for $80 \%$ (8/10) of the deaths in group II patients $(\mathrm{p}=0.24)$. Mean survival in group I was 83 months [95\% CI 70-97], and in group II it was 75 months [95\% CI 5992] (tab. III).

Recurrence of nonfatal sustained ventricular tachycardia was observed in $44(56.4 \%)$ patients, 26 being in group I $(57.8 \%)$ and 18 in group II $(54.5 \%)$. No difference between the 2 groups was observed in the recurrence of nonfatal sustained ventricular tachycardia (fig. 4). Recurrences of sustained ventricular tachycardia were accompanied by syncope in $26.9 \%$ of the patients, being more frequent in those who already had the symptom prior to antiarrhythmic

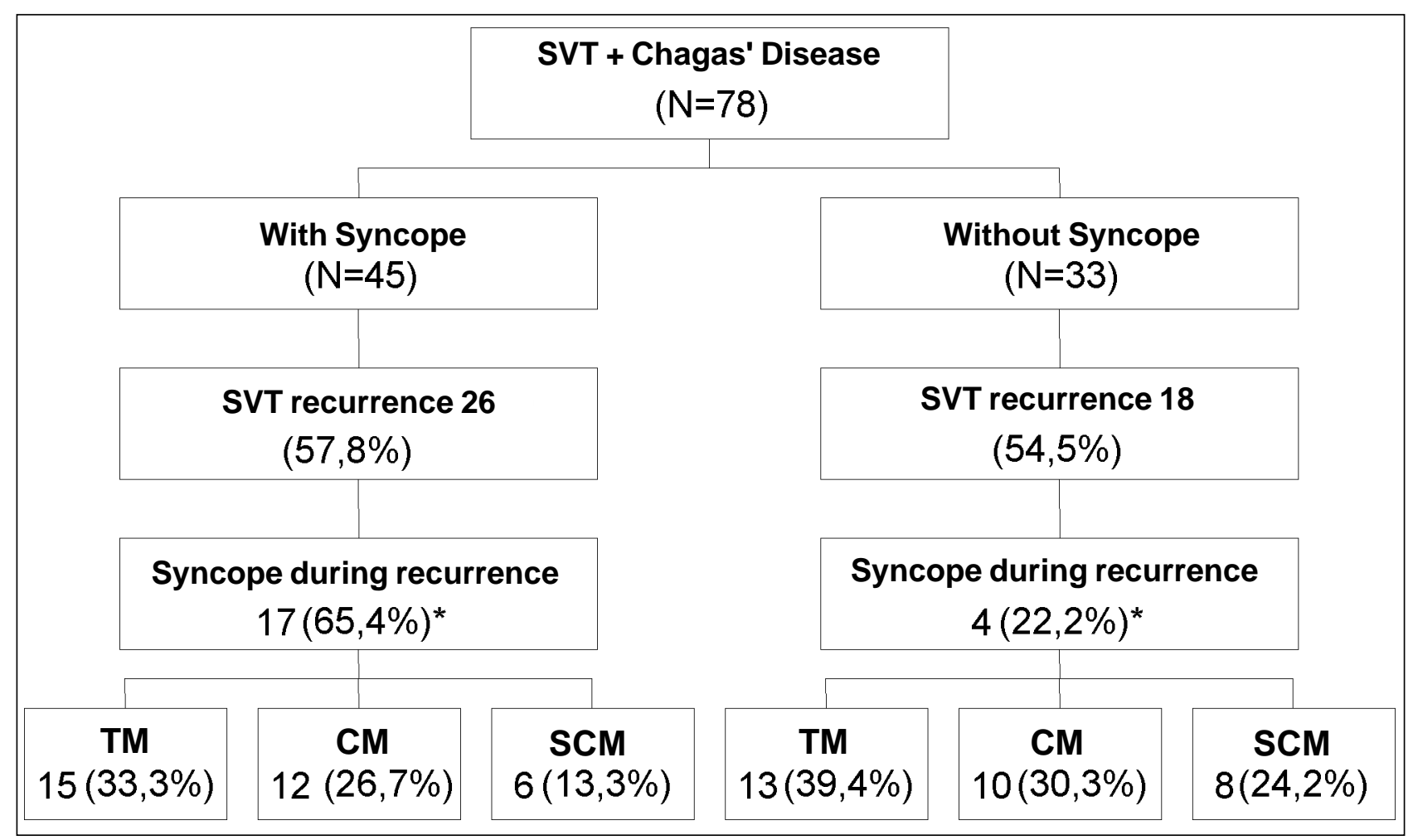

Fig. 1 - Events during clinical follow-up of patients with chronic chagasic heart disease according to the presence of syncope during clinical presentation of sustained ventricular tachycardia. TM- total mortality; CM- cardiac mortality; SCM- sudden cardiac mortality. 


\begin{tabular}{|lcccccc|}
\hline \multicolumn{2}{|c|}{ Table III - Total, cardiac, and sudden mortality, and recurrence of nonfatal sustained ventricular tachycardia in patients with chronic chagasic } \\
heart disease
\end{tabular}

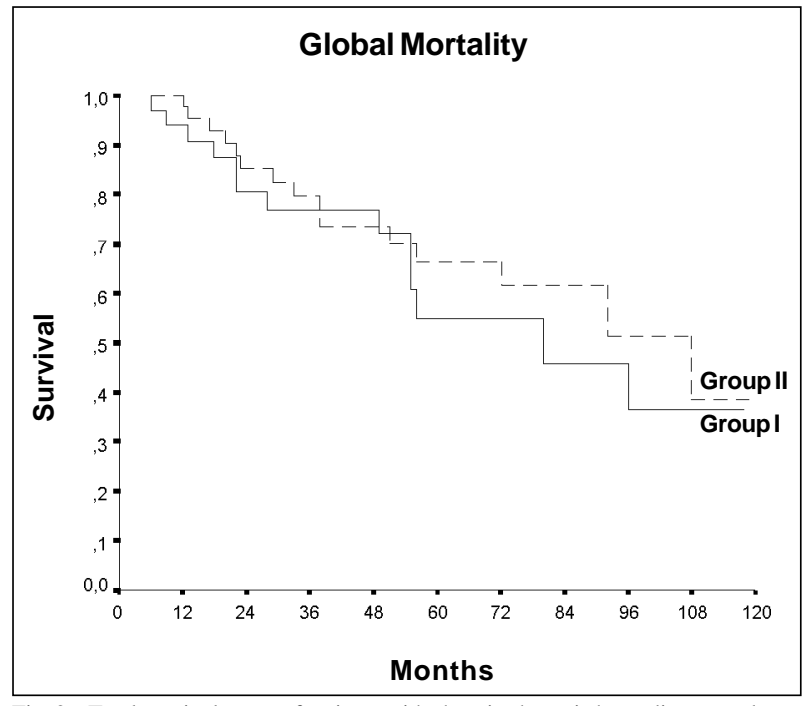

Fig. 2 - Total survival curve of patients with chronic chagasic heart disease and sustained ventricular tachycardia according to the presence of syncope during clinical presentation of the arrhythmia. Group I- with syncope; group II- without syncope.

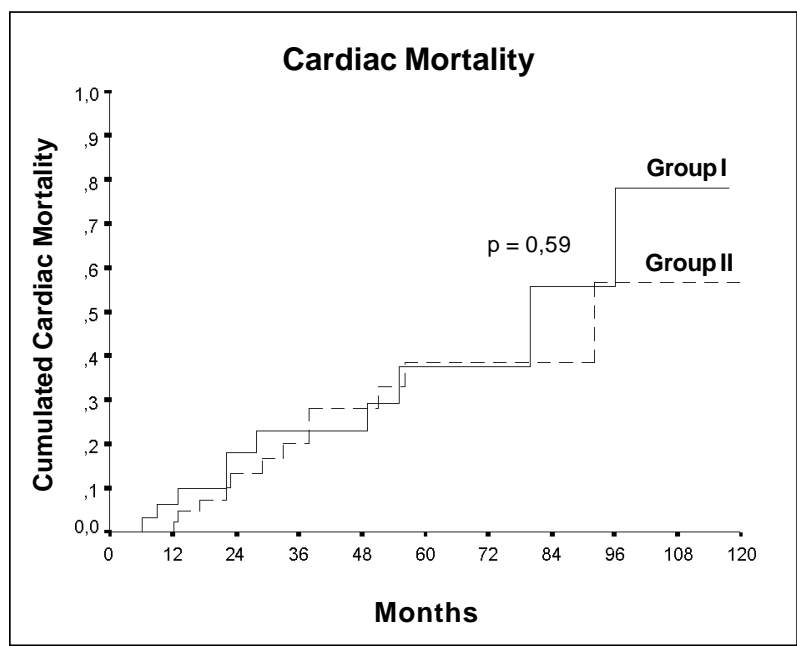

Fig. 3 - Curve of accumulated cardiac mortality in patients with chronic chagasic heart disease and sustained ventricular tachycardia according to the presence of syncope during clinical presentation of the arrhythmia. Group I- with syncope; group II- without syncope.

therapy. In the 26 group I patients with recurrence of nonfatal sustained ventricular tachycardia, $17(65.4 \%)$ experienced syncope; in the 18 group II patients with recurrence of nonfatal sustained ventricular tachycardia, $4(22.2 \%)$ experienced syncope $(\mathrm{p}<0.01)$.

To assess the importance of syncope associated with sustained ventricular tachycardia, the patients experiencing syncope at any time during the study were compared with those not experiencing it. Therefore, syncope associated with sustained ventricular tachycardia occurred in 4 of the 33 patients whose arrhythmia had initially occurred without syncope, adding to the 49 patients who experienced syncope associated with sustained ventricular tachycardia at any time during the study. When these 49 patients with syncope associated with sustained ventricular tachycardia were compared with the 29 without syncope, total $(36.7 \%$ vs. $34.5 \%, \mathrm{p}=0.91)$ and cardiac ( $24.5 \%$ and $34.5 \%)$ mortality did not differ at any time during the study.

Total and cardiac mortality was greater in the patients with left ventricular ejection fraction lower than $40 \%$. Of the 28 deaths occurring during total clinical follow-up, $50 \%$ of the patients had an ejection fraction lower than $40 \%$ as compared with $30.8 \%$ of the total population and $29 \%$ of the patients without this event; this difference, however, was not statistically significant.

\section{Discussion}

Our study assessed the impact of syncope during the

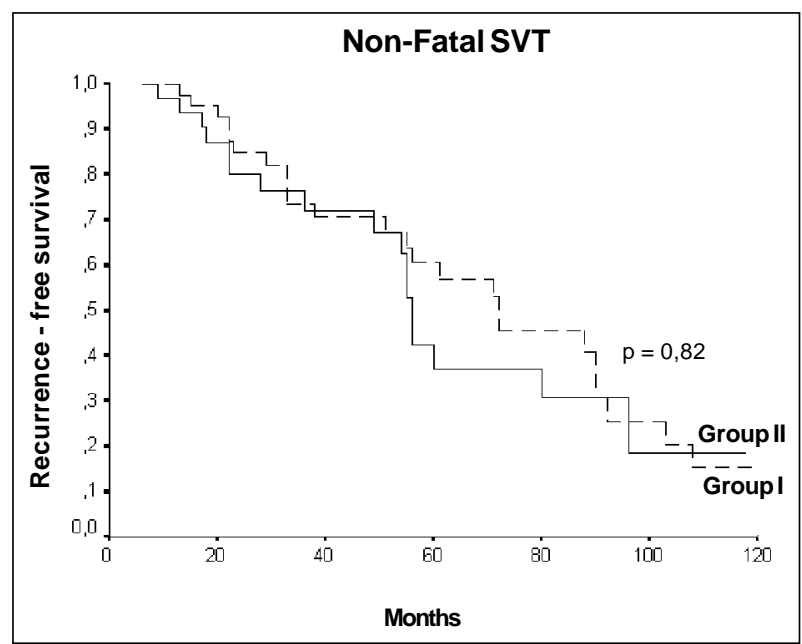

Fig. 4-Recurrence-free survival of nonfatal sustained ventricular tachycardia in patients with chronic chagasic heart disease and sustained ventricular tachycardia according to the presence of syncope during clinical presentation of the arrhythmia. 
clinical presentation of sustained ventricular tachycardia on total and cardiac mortality in patients with chronic chagasic heart disease. In our case series, the presence of syncope during sustained ventricular tachycardia, even though frequent $(57.7 \%)$, did not influence total and cardiac mortality in the long run.

Sustained ventricular tachycardia in patients with structural heart disease is a potentially lethal arrhythmia. Previous studies reported that, in the presence of structural cardiac impairment, mainly in ischemic heart disease, when sustained ventricular tachycardia is accompanied by syncope or cardiopulmonary arrest, the risk of a fatal recurrence is greater than when this arrhythmia is hemodynamically well tolerated ${ }^{1-5}$. In chronic chagasic heart disease, however, the impact of the presence of syncope during clinical presentation of sustained ventricular tachycardia has been studied less ${ }^{6-14}$.

Scanavacca et al ${ }^{9}$, studied 35 patients with sustained ventricular tachycardia and chronic chagasic heart disease treated with amiodarone. They showed that, despite recurrence of arrhythmia in $30 \%$ of the patients, no death was observed in patients with an ejection fraction $>30 \%$ and who were in functional class I or II during 27 months of clinical follow-up. In their study, cardiac mortality was $11.4 \%$, occurring in patients with severe ventricular dysfunction. However, the authors did not evaluate mortality according to the clinical presentation of the arrhythmia. Mendoza et al ${ }^{15}$ reported a mortality rate of $20 \%$ in patients with sustained ventricular tachycardia and chronic chagasic heart disease; however the importance of clinical presentation during the spontaneous arrhythmia in the evolution of these patients was not mentioned. In our study, total (33.3\% vs. $39.4 \%$, $\mathrm{p}=0.43$ ) and cardiac ( $26.7 \%$ vs. $30.3 \%, \mathrm{p}=0.59)$ mortality was similar in patients with and without syncope. These results may not be attributed to differences in clinical, electrophysiological, or therapeutical characteristics, because they were similar for both groups, and most patients were receiving amiodarone. The higher mortality rate in our study as compared with that in other studies may have been due to the larger size of our sample and our longer follow-up.

It is important to emphasize that when we analyzed only the patients with ejection fraction below $40 \%$, total, cardiac, and sudden deaths were similar in the patients with and without syncope. However, contrary to that which happens in coronary artery disease, but similar to that reported in other studies involving only patients with Chagas' disease ${ }^{6,15-18}$, sustained ventricular tachycardia occurred in patients with mild ventricular dysfunction, as shown by the mean ejection fraction of $49.6 \%$, and in only $30.8 \%$ of the patients with ejection fraction below $40 \%$. Bestetti et al ${ }^{6}$ reported ventricular dysfunction in $50 \%$ of the chagasic patients with sustained ventricular tachycardia studied with echocardiography; only $10 \%$ had severe dysfunction. In patients undergoing catheter ablation, Sosa et al ${ }^{16}$ reported a mean ejection fraction of $62 \%$, measured on echocardiography; these results were similar to those reported by Mendoza et al ${ }^{15}$, studying 15 chagasic patients with sustained ventricular tachycardia (mean ejection fraction of 56\%). The small number of patients with severe ventricular dysfunction in our population was certainly a limitation in evaluating the importance of syncope associated with sustained ventricular tachycardia when the ejection fraction was reduced.

In our study, we could also observe a similar recurrence rate of sustained ventricular tachycardia in patients with and without syncope ( $57.8 \%$ vs. $54.5 \%, \mathrm{p}=0.82)$; syncopal sustained ventricular tachycardia, however, was more frequent in patients who had the symptom from the beginning [17/26 (65.4\%) vs. 4/18 (22\%), p<0.01]. Our data suggest that the presence of syncope during sustained ventricular tachycardia does not increase the probability of recurrence. Patients with previous episodes of syncope, however, more commonly experience this symptom during recurrences of sustained ventricular tachycardia. Likewise, Scanavacca et $\mathrm{al}^{9}$ reported a $56 \%$ probability of recurrence of sustained ventricular tachycardia in 36 months, which was similar for patients with and without syncope or resuscitated sudden death at the beginning of the study. No reference to the presence or absence of syncope associated with recurrences was made in their study results.

Syncope in chronic chagasic heart disease may result from 3 factors: tachyarrhythmias, bradyarrhythmias, and autonomic dysfunction. Syncope associated with sustained ventricular tachycardia has a variable incidence reported in the literature ${ }^{6-10}$. In the study by Bestetti et al ${ }^{6}, 3$ out of 15 chagasic patients with sustained ventricular tachycardia had syncope, but only 1 during arrhythmia. Scanavacca et $\mathrm{al}^{9}$, in a similar population, reported syncope in $37 \%$ of the 35 patients studied. In patients with sustained ventricular tachycardia and chronic chagasic heart disease, who had undergone epicardial ablation, Sosa et al ${ }^{16}$ reported a $60 \%$ incidence of syncope and presyncope. This result was similar to the $62.5 \%$ incidence reported by de Paola et al ${ }^{10}$ in chagasic patients with sustained ventricular tachycardia undergoing angiographic and electrophysiological studies, and to the $58 \%$ found in our study.

Even though syncope has been studied in the context of chronic chagasic heart disease, specifically during the clinical presentation of sustained ventricular tachycardia, its importance as a prognostic determinant is not totally known. Martinelli et al ${ }^{13}$ carried out an electrophysiological study in 53 chagasic patients with recurring syncope and reported that mortality was significantly greater in the patients who had induced sustained ventricular tachycardia during programmed ventricular stimulation. Mendonça et al ${ }^{14}$ showed that inducibility of sustained ventricular tachycardia was greater in patients with nonsustained ventricular tachycardia and syncope, who evolved with cardiac death $(45.4 \%$ x $14.2 \%, \mathrm{p}<0.05)$. In these studies, however, no reference was made to the presence of syncope associated with spontaneous sustained ventricular tachycardia. Bestetti et $\mathrm{al}^{6}$, studying 74 patients with chagasic heart disease, reported that syncope was not a predictor of sudden death in this population. The authors did not include exclusively patients with sustained ventricular tachycardia, and, there- 
fore, the importance of the symptom when associated with the arrhythmia could not be determined.

The hemodynamic response to sustained ventricular tachycardia depends on several factors, which include ventricular dysfunction, atrioventricular synchronism, the frequency cycle of ventricular tachycardia, and the response of the autonomous nervous system ${ }^{19-20}$. However, the response of blood pressure and severity of the symptoms may vary even in patients with similar ventricular function and ventricular tachycardia frequency cycles ${ }^{19-23}$.

The frequency cycle of sustained ventricular tachycardia has been valued as 1 of the major markers of the hemodynamic response to ventricular tachycardia. Adhar et al ${ }^{21}$ reported that the frequency cycle of ventricular tachycardia induced by electrophysiological study was shorter when clinical ventricular tachycardia manifested with syncope. However, this difference did not persist after multivariate analysis. On the other hand, Landolina et al ${ }^{22}$ showed that hemodynamic deterioration resulted from impaired baroreflex sensitivity, and not from the ejection fraction and the frequency cycle of tachycardia. In our study, the frequency cycle of clinical sustained ventricular tachycardia of the patients with syncope (314 ms, 95\% CI 282-347) did not significantly differ from that observed in patients without syncope (309 ms, 95\% CI 282-337). However, a tendency (0.08) towards a shorter frequency cycle of induced sustained ventricular tachycardia was observed in patients in group I $296 \mathrm{~ms}$ (95\% CI 273-319)] as compared with those in group II [ $325 \mathrm{~ms}$ (95\% CI 299-351)]. Therefore, the presence of syncope in group I patients cannot be explained by the difference in the frequency cycle of sustained ventricular tachycardia.
Recently, Landolina et al ${ }^{22}$ and Hamdan et al ${ }^{23}$ reported that impaired baroreflex sensitivity correlated with hemodynamic deterioration during sustained ventricular tachycardia, and that the gain in arterial baroreflex significantly contributed to hemodynamic stability after initial deterioration. These studies were carried out in patients with coronary artery disease, in which severe impairment of the autonomous nervous system is an important prognostic factor, because it denotes an advanced stage of heart failure, the major predictor of mortality. Chagas' disease may affect the autonomous nervous system, independently from advanced cardiac impairment, or without advanced heart failure, and this may partially explain the mechanism of syncope in these patients, without resulting in an increase in mortality. However, because in our study no assessment of the autonomous nervous system was performed, no conclusion can be drawn in regard to its role in the occurrence of syncope in this population.

In conclusion, our data suggest that the presence of syncope during sustained ventricular tachycardia did not influence total, cardiac, or sudden mortality in the chagasic population treated with amiodarone, despite the high recurrence rate of the arrhythmia. In addition, the probability of occurrence of syncope during the recurrence of sustained ventricular tachycardia was greater in the patients who had previously experienced the symptom. Until more specific predictors of risk are identified, the management of chagasic patients who have sustained ventricular tachycardia should not be influenced by the presence of syncope during the clinical presentation of the arrhythmia.

\section{References}

1. Fogoros RN, Fiedler SB, Elson JJ. The automatic implantable cardioverter-defibrillator in drug-refractory ventricular tachyarrhythmias. Ann Intern Med 1987; 107: 635-41.

2. Kadish AH, Buxton AE, Waxman HL, Flores B, Josephson ME, Marchlinski FE. Usefulness of electrophysiologic study to determine the clinical tolerance of arrhythmia recurrences during amiodarone therapy. J Am Coll Cardiol 1987; 10: $90-6$.

3. Herre JM, Sauve MJ, Malone P, et al. Long-term results of amiodarone therapy in patients with recurrent sustained ventricular tachycardia or ventricular fibrillation. J Am Coll Cardiol 1989; 13: 442-9.

4. Brugada P, Talajic M, Smeets J, Mulleneers R, Wellens HJ. The value of the clinical history to assess prognosis of patients with ventricular tachycardia or ventricular fibrillation after myocardial infarction. Eur Heart J 1989; 10: 747-52.

5. Saxon LA, Uretz EF, Denes P. Significance of the clinical presentation in ventricular tachycardia/fibrillation. Am Heart J 1989; 118: 695-701.

6. Bestetti RB, Santos CRF, Machado Jr OB, et al. Clinical profile of patients with Chagas' disease before and during sustained ventricular tachycardia. Intern J Cardiol 1990; 29: 39-46.

7. Bestetti RB, Dalbo CMR, Arruda CA, Correia F ${ }^{\circ}$, Freitas OC. Predictors of sudden cardiac death for patients with Chags' disease: A hospital-derived cohort study. Cardiology 1996; 87: 481-7.

8. Prata AR, Lopes ER, Chapadeiro E. Características da morte súbita tida como não esperada na doença de Chagas. Rev Soc Bras Med Trop 1986; 19: 9-12.

9. Scanavacca MI, Sosa EA, Lee JH, Bellotti G, Pileggi F. Empiric therapy with amiodarone in patients with chronic Chagas cardiomyopathy and sustained ventricular tachycardia. Arq Bras Cardiol 1990; 54: 367-71.

10. de Paola AA, Melo WD, Tavora MZ, MartinezEE. Angiographic and electrophy- siological substrates for ventricular tachycardia mapping through the coronary veins. Heart 1998; 79: 59-63.

11. Távora MZ, Mehta N, Silva RM, Gondim FA, Hara VM, de Paola AA. Characteristics and identification of sites of chagasic ventricular tachycardia by endocardial mapping. Arq Bras Cardiol 1999; 72: 451-74.

12. Silva RMFL, Távora MZP, Gondin FAA, Metha N, Hara VM, de Paola AAV. Valor preditivo das variáveis clínicas e eletrofisiológicas em pacientes com cardiopatia chagásica crônica e taquicardia ventricular não sustentada. Arq Bras Cardiol 2000; 75: 41-7.

13. Martinelli Filho M, Sosa E, Nishioka S, Scanavacca M, Bellotti G, Pileggi F. Clinical and electrophysiologic features of syncope in chronic chagasic heart disease. J Cardiovasc Electrophysiol 19941; 5: 563-70.

14. Mendonça A, de Paola AAV, Hara MV, Metha N, Gondin FAA, Portugal OP. Variáveis clínicas e de função ventricular relacionada à mortalidade em pacientes com cardiopatia chagásica crônica e taquicardia ventricular não sustentada. Arq Bras Cardiol 1994; 63: 124.

15. Mendoza I, Camardo J, Molerio F, et al. Sustained ventricular tachycardia in chronic chagasic myocarditis: electrophysiologic and pharmacologic characteristics. Am J Cardiol 1986; 57: 423-7.

16. Sosa E, Scanavacca M, D’Avila A, et al. Endocardial and epicardial ablation guided by nonsurgical transthoracic epicardial mapping to treat recurrent ventricular tachycardia. J Cardiovasc Electrophysiol 1998; 9: 229-39.

17. Leite LR, Ponzi K, Fenelon G, Cintra F, Simões A, de Paola AAV. Preditores clínicos e eletrofisiológicos de sobrevida em pacientes com taquicardia ventricular e cardiopatia chagásica crônica. Análise multivariada. Reblampa 2000; 13: 175.

18. Leite LR, de Paola AAV, Pereira KP, Luna Filho B. Clinical usefulness of electrophysiologic testing in patients with sustained ventricular tachycardia and 
chronic chagasic cardiomyopathy treated with amiodarone and sotalol. PACE 2000; $23: 714$.

19. Hamer AW, Rubin SA, Peter T, Mandel WJ. Factors that predict syncope during ventricular tachycardia in patients. Am Heart J 1984; 107: 997-1005.

20. Steinbach KK, Merl O, Frohner K, et al. Hemodynamics during ventricular tachyarrhythmias. Am Heart J 1994; 127: 1102-6.

21. Adhar GC, Larson LW, Bardy GH, Greene HL. Sustained ventricular arrhyth- mias: differences between survivors of cardiac arrest and patients with recurrent sustained ventricular tachycardia. J Am Coll Cardiol 1988; 12: 159-65.

22. Landolina M, Mantica M, Pessano P, et al. Impaired baroreflex sensitivity is correlated with hemodynamic deterioration of sustained ventricular tachycardia. J Am Coll Cardiol 1997; 29: 568-75.

23. Hamdan MH,JoglarJA,Page RL, etal.Baroreflex gain predicts blood pressure recovery during simulated ventricular tachycardia in humans. Circulation 1999; 100: 381-6. 